\title{
Toplum Ruh Sağlığı Merkezi Uygulamalarının Şizofreni Hastalığının Sürecine Klinik Değişkenler Temelinde Etkisi
}

\author{
Onur DURMAZ1 ${ }^{1}$, Neslihan AKKİșİ KUMSAR ${ }^{2}$
}

\begin{abstract}
Özet: Bu çalışmada amaç, Toplum Ruh Sağlığı Merkezi (TRSM) uygulamalarının şizofreni hastalarında çeşitli klinik değişkenlere olan etkisini değerlendirmektir. Mayıs-Temmuz 2018 tarihleri arasında Erenköy Ruh ve Sinir Hastalıkları Eğitim ve Araştırma Hastanesi'ne bağlı bir TRSM merkezine başvurmuş ve aynı dönem TRSM takibinde olmayan ve yatırılarak tedavi almış şizofreni tanılı hastaların hastane sistemi üzerinden geriye dönük dosya incelemeleri yapılmıştır. Toplam 69 TRSM takipli ve 75 TRSM takibi olmayan hastanın verilerine ulaşılmıştır. Madde kullanım öyküsü, vesayet kararı TRSM takibi olmayan hastalarda belirgin olarak yüksek saptandı $(\mathrm{p}=0.01, \mathrm{p}=0.005)$. Ortanca zorunlu yatış sayıları, TRSM takibi olmayan grupta TRSM takipli gruba göre anlamlı daha yüksek idi $(\mathrm{p}<0.001)$. TRSM takibi öncesi ortanca acil başvuruları kıyaslandığında iki grup arasinda anlamlı fark bulundu (TRSM takipli grup=2(1-5), TRSM takibi olmayan grup=5(2-11); $\mathrm{p}<0.001$ ). TRSM takipli grupta, TRSM takibi öncesi ve sonrası acil servis başvurularına bakıldığında hastaların ortalama acil başvurularının önemli kısmının TRSM takibi öncesinde olduğu gözlenmiştir (TRSM takibi öncesi ortalama başvuru sayısı $=4.2 \pm 6.2$, TRSM takibi sonrası başvuru sayısı $=1.3 \pm 3.1$ ). Bulgular, TRSM takibiyle yatırılarak tedavi ve acil servis müracaat miktarlarında anlamlı düşme olabileceği lehinedir. Ayrıca vesayet kararlarının ve zorunlu yatı̧s sayılarının da TRSM takibi olmayan hastalarda daha yüksek olduğu gözlenmiştir.
\end{abstract}

Anahtar Kelimeler: Rehabilitasyon, Şizofreni, Toplum Ruh Sağlı̆̆

\section{Impact Of Community Mental Health Centers To Clinical Variables Of Schizophrenia}

\begin{abstract}
Aim of current study was to investigate the impact of Community Mental Health Center(CMHC) interventions to outcome in schizophrenia patients. Data between May 2018-July 2018 retrieved from hospital database belonged to 69 outpatient schizophrenia patients who were following in a CMHC of Erenköy Training and Research Hospital for Mental Health and Neurological Diseases (CMHCH group) and 75 hospitalized schizophrenia subjects had not been involved in CMHC services (Non-CMHC group) was included in study. Substance use history and number of patients who were given a medical board report to place under guardianship were significantly higher in non-CMHC group $(\mathrm{p}=0.01, \mathrm{p}=0.005$; respectively). Involuntary admissions was found to be significantly higher in non-CMHC group ( $\mathrm{p}<0.001)$. By comparison, there was a significant difference in terms of emergency visits between groups before involving to CMHC relative to nonCMHC group (CMHC group=2(1-5), non-CMHC group=5(2-11); $<<0.001)$. A vast majority of emergency visits in $\mathrm{CMHC}$ group was conducted before involving to $\mathrm{CMHC}$ services (Before $\mathrm{CMHC}$ involvement $=4.2 \pm 6.2$, after $\mathrm{CMHC}$ involvement $=1.3 \pm 3.1$ ). Our results suggest that a significant decrease in emergency visits and hospitalizations might be associated with a CMHC follow up in schizophrenia. Involuntary admissions and placing under guardianship were also higher in those who were not under CMHC follow up.
\end{abstract}

Keywords: Rehabilitation, Schizophrenia, Community Mental Health Service

Uzm. Dr., Erenköy Ruh ve Sinir Hastalıkları Eğitim ve Araştırma Hastanesi, Psikiyatri Servisi, İstanbul-Turkiye, Orcid İd: https://orcid.org/ 0000-0002-0876-7658

Doç. Dr., Erenköy Ruh ve Sinir Hastalıkları Eğitim ve Araştırma Hastanesi, Psikiyatri Sevisi, İstanbul-Turkiye, Orcid İd: https://orcid.org/ 0000-0002-5010-6466

Address of correspondence/Yazışma adresi: Uzm. Dr., Onur DURMAZ Erenköy Ruh ve Sinir Hastalıkları Eğitim ve Araştırma Hastanesi, Psikiyatri Servisi İstanbul-Turkiye E.mail: drodurmaz@ gmail.com

Date of Received/Geliş Tarihi: 18.04.2020, Date of Revision/Düzeltme Tarihi: 10.06.2020, Date of Acceptance/Kabul Tarihi: 14.06 .2020

Citing/ Referans Gösterimi: Durmaz, O. ve Akkişi Kumsar, N. (2020). Toplum Ruh Sağlı̆̆ı Merkezi Uygulamalarının Şizofreni Hastalığının Sürecine Klinik Değişkenler Temelinde Etkisi. Kıbrıs Türk Psikiyatri ve Psikoloji Dergisi, 2(2): 82-88 doi:10.35365/ctjpp.20.02.12 


\section{Giriş}

Dünya Sağlık Örgütü(DSÖ)'nün verilerine göre ruhsal bozukluklar tüm dünyada toplam yeti yitiminin \%12-15, inden sorumlu tutulmakta olup bu oran en sik görülen kalp-damar hastalıklarından daha yüksektir (Thornicroft G, 2003). Şizofreni başta olmak üzere ruhsal bozuklukların kronik seyri ve zaman içerisinde giderek artan yeti yitimi yaratması, maliyet açısından büyük yükler getiren bu bozuklukların tedavilerinde biyopsikososyal modelin ön plana çıkmasına sebep olmuştur. $\mathrm{Bu}$ bağlamda veriler gerek hastane odaklı yaklaşımların gerekse ayaktan tedavi yaklaşımlarının tek başına yeterli olamayacağını göstermektedir (Thornicroft G 2003). Hastane odaklı yaklaşımların hastalarda özellikle istemsiz yatış süreçlerinde travmatik deneyimler yaratması, kötü muamele ve insan hakları gibi hususlarda sorunları beraberinde getirmesi ve damgalanma gibi özellikle şizofrenide halen çözülememiş bir toplumsal sorunu artırıc1 etki yaratmas1, toplum odakl1 ve ailenin de kapsandığ 1 ruhsal tedavi seçeneklerini ruh sağlığ politikalarında kritik hale getirmektedir (Hughes ve ark. 2009; Lee ve ark. 2006; Tsigebrhan ve ark. 2014). İstemsiz yatırılarak uygulanan tedavi müdahalelerinin hastaların tedaviye yaklaşımlarında olumsuz etki yaratabileceği ve ileriki tedavilerinde de zorunlu müdahalelere ihtiyaç duyulması açısından yordayıcı olabileceğine yönelik veriler bulunmaktadır (Hughes ve ark. 2009; Jaeger ve ark. 2013). Ayrıca şizofreni hastalarının özellikle gelişmemiş ve gelişmekte olan ülkelerde tedaviye ulaşımlarının kısıtlı olması da hastalara ulaşım açısından yeni yöntemlerin geliştirilmesi gerekliliğini ortaya çıkarmıştır (Asher ve ark. 2018; Tsigebrhan ve ark. 2014). Bu bağlamda dünyada toplum temelli ruh sağlığı hizmetlerinin artması ile birlikte büyük akıl hastanelerinin sayıları azaltılmış ve bölgesel ayaktan rehabilitasyon merkezler açılmaya başlanmıştır. Benzer şekilde ülkemizde de 2008 yılından itibaren DSÖ'nün önerileri de dikkate alınarak toplum temelli ruhsal iyileştirme kapsamında Toplum Ruh Sağlı̆̆1 Merkezleri(TRSM) kurulmuştur (Alataş ve ark. 2009; Ensari ve ark. 2013). Bu merkezler 150.000-250.000 aralığında bir nüfusa hizmet verecek kapasitede olup bünyesinde ruh sağlığı uzmanı hekim, hemşire, psikolog, sosyal hizmet uzmanı ve uğraşı terapisti barındıran evde sağlık hizmeti verebilecek gezici ekibi bulunan gündüz hizmet veren merkezler olarak tasarlanmışlardır. $\mathrm{Bu}$ merkezlerde amaç sadece hastanın ilaç tedavilerini düzenlemek değil, çoklu disipliner yaklaşım ekseninde hastaların gündelik yaşantılarında becerilerini geliştirmek, danışanlara ve yakınlarına rahatsızlıkları ile ilgili bilgilendirme eğitimleri vermek, rehabilitasyon programları uygulamak, çeşitli kurslar ve sosyal aktiviteler düzenlemek, damgalama ile mücadele, çeşitli devlet kurumları ile irtibata geçerek danışanların geçim, barınma ve meslek edinme gibi çeşitli yaşam sorunları ile ilgilenmek olarak özetlenebilmektedir. Ülkemizde TRSM hizmetleri ile ilgili veriler kısıtlıdır (Yanık, 2007). Ensari ve arkadaşları tarafından ülkemizde ilk kez TRSM hizmetinin yürürlüğe girdiği Bolu TRSM' de yapılmış olan 30 şizofreni hastasının dahil edildiği bir yıllık izlem çalışmasında TRSM takibi sonrası hastaların yaşam kalitelerinin ve işlevselliklerinin arttığ , yeti yitiminin azaldığ 1 bildirilmiştir (Ensari ve ark. 2013). Şizofrenide tedaviye katılımın ve tedaviye ulaşımın yetersiz olması hastalığın kronikleşmesine, yeti yitiminde artışa ve sık alevlenmeler neticesi acil servise müracaat, zorunlu yatışlarda ve müdahalelerde artışlara sebep olmakta ve netice olarak kişinin yaşamını kendi başına idame ettiremeyeceği noktada vesayet gibi hukuki kararlara kadar sürecin ilerlemesine neden olabilmektedir. Bildiğimiz kadarıyla, ülkemizde TRSM uygulamalarının şizofreni hastalarında yatırılarak tedavi, zorunlu yatış karar1, vesayet ve acil servise müracaat gerekliliği gibi klinik ve yeti yitimi ile ilişkili veriler üzerine etkilerini araştıran bir çalışma bulunmamaktadır. $\mathrm{Bu}$ noktadan hareketle bu çalışmada amaç, TRSM tarafından takip edilen ve yatırılarak tedavi görmüş fakat TRSM takibi olmayan şizofreni hastalarında; zorunlu yatış kararı, vesayet ve acil servise müracaat gerekliliği gibi klinik değişkenler açısından bir farklılık olup olmadığını araştırmak ve TRSM uygulamalarının bu değişkenler zemininde şizofreni tedavisinde etkinliğini ortaya koymaktır. Araştırmanın problemleri şu şekilde siralanabilir:

1-TRSM takibi olan ve olmayan şizofreni hastalarında sosyo demografik veriler ve klinik değişkenler açısından anlamlı farklılık var midır?

2- Şizofreni hastalarında TRSM takibi acil servis müracaatlarını ve yatış kararlarını etkilemekte midir?

3-Şizofreni hastalarında TRSM takipleri ile acil servis müracaatları ve yatış miktarları arasında bir ilişki mevcut mudur?

\section{Yöntem}

\section{Veri Toplama Araçları ve Örneklem}

Çalışmada, Mayıs 2018-Temmuz 2018 tarihleri arasında hastanemize bağlı hizmet veren bir TRSM kapsamında takip edilmiş olan hastaların ve yine aynı dönemde hastanemizde yatırılarak tedavi edilmiş ancak TRSM takibi olmayan hastaların dosyaları ardışık olarak taranmıştır. Hastane veri tabanı kullanılarak hastaların geriye dönük olarak epikrizleri, poliklinik müracaatları sonrası kaydedilmiş olan muayene ve amnezi bilgileri kullanılarak sosyo-demografik verilerine ve klinik değişkenlerine yönelik verilere ulaşılmıştır. Toplam 69 TRSM takipli şizofreni hastası ile aynı tarihlerde hastanemizde yatırılarak tedavi görmüş ancak TRSM takibi olmayan 75 adet şizofreni hastasının verilerine ulaşılmıştır. Şizofreni dışı tanı alan, TRSM takibi almamış sadece ayaktan tedavi görmüş olan, verileri yetersiz olarak değerlendirilen hastalar çalışma dışında tutulmuştur.

\section{Verilerin Analizi}

Verilerin normallik dağılımları Kolmogorov-Smirnov testi ile değerlendirilmiştir. Normal dağılıma uyan sürekli değişkenlerin karşılaştırılmasında bağımsız $\mathrm{t}$ testi, normal dağılıma uymayan sürekli değişkenlerin değerlendirilmesinde Mann-Whitney U testi kullanılmıştır. Bağımsız grupların kategorik değişkenlerinin karşılaştırılmasında Ki-Kare testi, bağımlı grupların sürekli değişkenlerinin karşılaştırılmasında Wilcoxon testi, kategorik değişkenleri için ise McNemar testi kullanılmıştır. Kategorik verilerin karşılaştırılmasında etki büyüklüğü Cramer's V değeri ile, sürekli değişkenlerin karşılaştırılmasında etki büyüklüğü cohen's d değeri ile gösterilmiştir. Normal dağılımlı sürekli veriler ortalama \pm 
standart sapma ile gösterilmiş olup normal dağılımlı gösterilmiştir. TRSM takipli hastaların klinik verileri arasındaki ilişkilerin belirlenmesinde Pearson korelasyon analizi kullanılmıştır. İstatistiksel anlamlılık düzeyi

\section{Bulgular}

Tablo 1. Sosyodemografik Veriler

\begin{tabular}{|c|c|c|c|c|c|c|c|c|}
\hline & \multicolumn{2}{|c|}{$\begin{array}{c}\text { TRSM takipli } \\
(\mathrm{n}=69)\end{array}$} & \multicolumn{2}{|c|}{$\begin{array}{c}\text { TRSM takipsiz } \\
(\mathrm{n}=75)\end{array}$} & Ki-Kare & Cramer's V & $\mathrm{t}$ & $\mathrm{p}$ \\
\hline \multirow[t]{2}{*}{ Yaş } & \multicolumn{2}{|c|}{$42 \pm 12,8$} & \multicolumn{2}{|c|}{$44,5 \pm 12,4$} & & & -1.18 & 0.23 \\
\hline & $\mathrm{n}$ & $\%$ & $\mathrm{n}$ & $\%$ & & & & \\
\hline \multicolumn{9}{|l|}{ Cinsiyet } \\
\hline Kadın & 27 & 39.1 & 34 & 45.3 & 0.56 & 0.06 & & 0.45 \\
\hline Erkek & 42 & 60.9 & 41 & 54.7 & & & & \\
\hline \multicolumn{9}{|l|}{ Medeni Durum } \\
\hline Bekar & 35 & 50.7 & 41 & 54.7 & 0.22 & 0.03 & & 0.89 \\
\hline Evli & 25 & 36.2 & 25 & 33.3 & & & & \\
\hline Boşanmış & 9 & 13.1 & 9 & 12 & & & & \\
\hline \multicolumn{9}{|l|}{ Eğitim } \\
\hline Eğitimsiz & 5 & 7.2 & 6 & 8 & 0.51 & 0.06 & & 0.91 \\
\hline İlköğretim & 43 & 62.3 & 50 & 66.7 & & & & \\
\hline Ortöğretim & 16 & 23.2 & 15 & 20 & & & & \\
\hline Yükseköğretim & 5 & 7.2 & 4 & 5.3 & & & & \\
\hline \multicolumn{9}{|l|}{ Calısma Durumu } \\
\hline Çalışmıyor & 64 & 92.8 & 69 & 92 & 0.77 & 0.07 & & 0.68 \\
\hline Calıșiyor & 3 & 4.3 & 5 & 6.7 & & & & \\
\hline Emekli & 2 & 2.9 & 1 & 1.3 & & & & \\
\hline \multicolumn{9}{|l|}{ Madde Kullanımı } \\
\hline Öyküsü & 65 & 94.2 & 62 & 82.7 & 4.59 & 0.17 & & 0.03 \\
\hline Yok & 4 & 5.8 & 13 & 17.3 & & & & \\
\hline \multicolumn{9}{|l|}{ Var } \\
\hline \multicolumn{9}{|l|}{ Vesayet } \\
\hline Var & 16 & 23.2 & 34 & 45.3 & 7.77 & 0.23 & & 0.005 \\
\hline Yok & 53 & 76.8 & 41 & 54.7 & & & & \\
\hline
\end{tabular}

Çalıșmaya dâhil edilen TRSM takipli hastaların yaș ortalamas1 $42 \pm 12,8$ y1l, TRSM takibi olmayan hastaların yaş ortalamas 1 ise $44,5 \pm 12,4$ yıl olarak saptand1 $(t=-1.18$, $\mathrm{p}=0.23$ ). Her iki grup arasında medeni durum, eğitim, çalışma durumu açısından anlamlı fark olmayan sürekli veriler ise ortanca(\%25-75) değerleri ile olarak $\mathrm{p}<0.05$ değeri kabul edilmiştir. İstatistiksel değerlendirmeler SPSS 20.0 programı kullanılarak yapılmıştır.

Tablo 2. TRSM takipli olan ve olmayan hastaların klinik verilerinin karşıllaştırılması

\begin{tabular}{|c|c|c|c|c|c|}
\hline & $\begin{array}{l}\text { TRSM takipli } \\
\quad(\mathrm{n}=69)\end{array}$ & $\begin{array}{l}\text { TRSM takipsiz } \\
\quad(\mathrm{n}=75)\end{array}$ & Cohen's d & Z & $\mathrm{p}$ \\
\hline Hastalık Süresi & $11.5(6-20)$ & $15(8,25-22,25)$ & 0.26 & -1.74 & 0.08 \\
\hline$Y_{11}(\% 25-75)$ & & & & & \\
\hline Toplam Takip Süresi & $91(49,75-117)$ & $101.5(40.75-123)$ & 0.02 & -0.13 & 0.89 \\
\hline $\operatorname{Ay}(\% 25-75)$ & & & & & \\
\hline Toplam Acil Başvuru & $3(1-5)$ & $5(2-11)$ & 0.34 & -4.07 & $<0.001$ \\
\hline Say1s1(\%25-75) & & & & & \\
\hline Toplam Yatış Sayısı(\%25-75) & $2(1-4)$ & $3(2-6)$ & 0.51 & -3.35 & 0.001 \\
\hline Zorunlu Yatış Sayısı(\%25-75) & $0(0-1)$ & $1(0-2)$ & 0.58 & -3.51 & $<0.001$ \\
\hline
\end{tabular}

Toplam hastalık süreleri açısından her iki grup arasında anlamlı ve büyük bir fark yoktu(d=0.26, $\mathrm{p}=0.08$; Tablo 2). Hastanemizde yapılmış toplam takip süreleri açısından da gruplar arasında anlamlı ve büyük bir fark saptanmadi $(\mathrm{d}=0.02, \mathrm{p}=0.89$; Tablo 2$)$. Ancak toplam acil başvuru sayısı, toplam yatış sayısı ve zorunlu yatış sayısı ortanca değerleri TRSM takibi olmayan hasta grubunda anlamlı düzeyde daha yüksekti(sırasıyla, $\mathrm{d}=0.34 \mathrm{p}<0.001$, $\mathrm{d}=0.51 \mathrm{p}=0.001, \mathrm{~d}=0.58 \mathrm{p}<0.001$; Tablo 2). Toplum Ruh Sağlığı Merkezi takipli hastaların TRSM takibi öncesi ve saptanmadı( $p>0.05$; Tablo 1).Geçmiște madde kullanımı öyküsü ve alınmış vesayet kararı açısından her iki grup karşılaştırıldığında TRSM takipli olmayan hastalarda madde kullanım öyküsünün ve vesayet kararının daha sık olduğu gözlendi(sırasıyla, $\mathrm{p}=0.03, \mathrm{p}=0.005$; Tablo 1 ). sonrası verileri karşılaştırıldığında, TRSM ortalama takip süresi $20.1 \pm 13.4$ ay iken TRSM kapsamına alınmadan önceki dönemde hastanedeki ortalama takip süresi $61.4 \pm 37$ ay olarak saptandı. Toplum Ruh Sağlığı Merkezi takipli hastaların ortanca TRSM başvuru sayıları 38 (15.5-80), TRSM takibi öncesi ortanca acil başvuru sayısı 2 (1-5), TRSM takibi başladıktan sonra acil başvuru sayısı $0(0-1.5)$, TRSM takibi öncesi ortanca yatış sayısı 1 (1-3.5), TRSM takibi başladıktan sonra ortanca yatış sayıs1 $0(0-0)$ olarak saptand1. 
Tablo 3. TRSM öncesi ve sonrası acil başvuruları ve yatırılarak tedavi sayıları açısından hastaların karşılaştırılması

\begin{tabular}{|c|c|c|c|c|}
\hline & \multicolumn{2}{|c|}{ TRSM Sonrası Acil Başvurusu } & \multirow{2}{*}{ Ki-Kare } & \multirow[t]{2}{*}{$\mathrm{p}^{*}$} \\
\hline & Yok & Var & & \\
\hline \multicolumn{5}{|l|}{ TRSM Öncesi Acil Başvurusu } \\
\hline Yok & 10 & 3 & 24.3 & $<0.001$ \\
\hline \multirow[t]{2}{*}{ Var } & 34 & 22 & & \\
\hline & $\begin{array}{l}\text { TRSM Sonras1 } \\
\text { Yok }\end{array}$ & Tedavi & & \\
\hline \multicolumn{5}{|l|}{ TRSM Öncesi Yatırılarak Tedavi } \\
\hline Yok & 4 & & 40.4 & $<0.001$ \\
\hline \multirow[t]{2}{*}{ Var } & 53 & & & \\
\hline & TRSM Öncesi & TRSM Sonras1 & $\mathrm{Z}$ & $\mathrm{p}^{* *}$ \\
\hline $\begin{array}{l}\text { Acil Başvuru Sayıs } \\
(\% 25-75)\end{array}$ & $2(1-5)$ & $0(0-1)$ & -4.4 & $<0.001$ \\
\hline $\begin{array}{l}\text { Toplam Hastane Yatış Sayısı(\%25- } \\
\text { 75) }\end{array}$ & $1(1-3.5)$ & $0(0-0)$ & -6.1 & $<0.001$ \\
\hline
\end{tabular}

*McNemar Testi, **Wilcoxon Testi

Acil başvuruları ve yatış sayıları karşıllaştırıldığında TRSM takibi ile birlikte acil başvurusu ve yatışı olan hasta sayılarında anlamlı derecede azalma olduğu gözlendi( sırasılyla Ki-kare $=40.3$ p $<0.001$, Ki-kare $=20.4$ $\mathrm{p}<0.001$; Tablo 3). Yapılan bağımlı grupların karşılaştırmasında TRSM sonrası ortanca acil servis başvuru sayısı ve hastane yatış sayısında anlamlı azalma saptand 1 (sirasiyla $\mathrm{z}=-4.4 \mathrm{p}<0.001, \mathrm{z}=-6.1 \mathrm{p}<0.001$; Tablo
3). Yapılan korelasyon analizinde ise TRSM takipli hastalarda TRSM takip süresi ile TRSM sonrası acil başvuru sayısı arasında pozitif korelasyon saptanırken $(\mathrm{r}=0.34 \mathrm{p}=0.003)$, TRSM öncesi acil başvuru sayısı ile arasinda korelasyon $\operatorname{saptanmad} 1(\mathrm{r}=0.05 \mathrm{p}=0.68)$. Ayrica TRSM öncesi ve sonrası acil başvuru sayıları arasında da korelasyon yoktu $(\mathrm{r}=0.21 \mathrm{p}=0.07)$.

Tablo 4. TRSM verileri, acil servis başvuruları ve yatırılarak tedavi sayıları açısından TRSM takipli hastalarda korel

\begin{tabular}{|c|c|c|c|c|c|c|c|c|c|c|c|c|c|c|}
\hline & \multirow{3}{*}{\multicolumn{2}{|c|}{$\begin{array}{c}\text { TRSM } \\
\text { Başvuru } \\
\text { Sayısı }\end{array}$}} & \multirow{4}{*}{\multicolumn{2}{|c|}{$\begin{array}{c}\text { TRSM } \\
\text { Öncesi Acil } \\
\text { Başvuru } \\
\text { Sayısı }\end{array}$}} & \multirow{3}{*}{\multicolumn{2}{|c|}{$\begin{array}{c}\text { TRSM Sonrası } \\
\text { Acil Başvuru } \\
\text { Sayısı }\end{array}$}} & \multirow{2}{*}{\multicolumn{2}{|c|}{$\begin{array}{c}\text { Toplam Acil } \\
\text { Başvuru Sayısı }\end{array}$}} & \multirow{2}{*}{\multicolumn{2}{|c|}{$\begin{array}{l}\text { TRSM Öncesi } \\
\text { Yatış Sayısı }\end{array}$}} & \multirow{2}{*}{\multicolumn{2}{|c|}{$\begin{array}{c}\text { TRSM Sonrası } \\
\text { Yatış Sayısı }\end{array}$}} & \multirow{2}{*}{\multicolumn{2}{|c|}{$\begin{array}{cc}\text { Toplam Yatış Sayısı } \\
\mathrm{r} & \mathrm{p}\end{array}$}} \\
\hline & & & & & & & & & & & & & & \\
\hline & & & & & & & $r$ & $\mathrm{p}$ & $\mathrm{r}$ & $\mathrm{p}$ & $\mathrm{r}$ & $\mathrm{p}$ & & \\
\hline & \multirow[t]{2}{*}{$\mathrm{r}$} & \multirow[t]{2}{*}{$\mathrm{p}$} & & & \multirow[t]{2}{*}{$\mathrm{r}$} & \multirow[t]{2}{*}{$\mathrm{p}$} & & & & & & & & \\
\hline & & & $\mathrm{r}$ & $\mathrm{p}$ & & & & & & & & & & \\
\hline TRSM & $0 . .2$ & 0.03 & 0.05 & 0.68 & 0.34 & 0.003 & 0.18 & 0.12 & -0.05 & 0.66 & 0.13 & 0.27 & -0.01 & 0.88 \\
\hline Takip & 6 & & & & & & & & & & & & & \\
\hline \multicolumn{15}{|l|}{ Süresi } \\
\hline TRSM & & & - & 0.43 & 0.23 & 0.06 & 0.01 & 0.89 & 0.15 & 0.23 & 0.22 & 0.07 & 0.2 & 0.1 \\
\hline Başvuru & & & 0.09 & & & & & & & & & & & \\
\hline \multicolumn{15}{|l|}{ Say1s1 } \\
\hline TRSM & & & & & 0.21 & 0.07 & $0 . .9$ & $<0.00$ & 0.29 & 0.01 & -0.05 & 0.66 & 0.27 & 0.02 \\
\hline Öncesi & & & & & & & 1 & 1 & & & & & & \\
\hline \multicolumn{15}{|l|}{ Acil } \\
\hline \multicolumn{15}{|l|}{ Başvuru } \\
\hline \multicolumn{15}{|l|}{ Say1S1 } \\
\hline TRSM & & & & & & & 0.59 & $<0.00$ & 0.22 & 0.06 & 0.13 & 0.27 & 0.24 & 0.03 \\
\hline Sonrasi & & & & & & & & 1 & & & & & & \\
\hline \multicolumn{15}{|l|}{ Acil } \\
\hline \multicolumn{15}{|l|}{ Başvuru } \\
\hline \multicolumn{15}{|l|}{ Say1S1 } \\
\hline Toplam & & & & & & & & & 0.33 & 0.005 & 0.01 & 0.91 & 0.32 & 0.006 \\
\hline \multicolumn{15}{|l|}{ Acil } \\
\hline \multicolumn{15}{|l|}{ Başvuru } \\
\hline Say1S1 & & & & & & & & & & & & & & \\
\hline TRSM & & & & & & & & & & & 0.01 & 0.89 & 0.96 & $<0.001$ \\
\hline Öncesi & & & & & & & & & & & & & & \\
\hline Yatış & & & & & & & & & & & & & & \\
\hline Say1s1 & & & & & & & & & & & & & & \\
\hline TRSM & & & & & & & & & & & & & 0.26 & 0.02 \\
\hline Sonras1 & & & & & & & & & & & & & & \\
\hline Yatış & & & & & & & & & & & & & & \\
\hline Say1s1 & & & & & & & & & & & & & & \\
\hline
\end{tabular}


Bununla birlikte, TRSM öncesi ve sonrası acil başvuru sayıları ile toplam yatış sayısı arasında pozitif korelasyon mevcuttu (sirasiyla $\mathrm{r}=0.27 \mathrm{p}=0.02, \mathrm{r}=0.24 \mathrm{p}=0.003$; Tablo 4). Toplam acil başvuru sayısı ile TRSM öncesi ve toplam yatış sayıları arasında ise pozitif korelasyon saptand 1 (sirasiyla $\mathrm{r}=0.33 \mathrm{p}=0.005, \mathrm{r}=0.32 \mathrm{p}=0.006$; Tablo 4).

Toplum Ruh Sağlığ1 Merkezi tarafindan takip edilen hastaların 22 tanesi henüz 1 yıldan daha az süredir TRSM takibi altında iken, 47 hasta (\% 68.1) 1 y1lın üzerinde bir süredir (ortalama $25.9 \pm 11.4$ ay) TRSM takibi altında idi. Toplum Ruh Sağlığ 1 tarafından takibi 1 ylldan uzun süredir devam eden hastaların 26's1 (\%55.3) TRSM takibi sonrası acil servise başvurmamışken aynı grupta TRSM takibi sonrası yatırılarak tedavi görmeyen hasta sayıs1 36(\%76.6) olarak saptand1. Aynı hasta grubunda TRSM öncesi ve TRSM takibi başladıktan sonra acil başvuruları ve yatırılarak tedavi sayıları karşılaştırıldığında anlamlı fark bulundu( TRSM öncesi ortanca acil başvurusu= 2 (1$5)$, TRSM sonrası ortanca acil başvurusu $=0(0-2), Z=-$ $3.06, \mathrm{p}=0.002$; TRSM öncesi ortanca yatış sayısı $=1(1-4)$, TRSM sonrası ortanca yatış sayısı $=0(0-0), Z=-4.7$, $\mathrm{p}=<0.001)$.

\section{Tartıșma}

Çalışmada, TRSM uygulamalarının yatırılarak tedavi gören şizofreni hastalarının tedavi süreçlerine ve klinik değişkenlerine olan etkilerini inceledik. Çalışmanın sonuçları TRSM uygulamalarının, hastaların istemsiz yatış sayıları da dahil olmak üzere yatış sayıları ve acil başvuruları açısından olumlu etkileri olduğunu destekler niteliktedir. Şizofreni hastalarında gerek tedavi katılımlarındaki kısıtlılıklar gerek hastalığın kronik seyri ve alevlenen bulguları nedeniyle acil servis başvuruları sık olarak karşımıza çıkmaktadır (Law ve ark. 2008). Yapılan bir çalışmada acil servis müracaatlarının \%5.4'ünün psikiyatrik nedenlerle olduğu, bu grubun $\% 21$ ' ini de şizofreni de dahil olmak üzere psikotik spektrumda bozuklukların oluşturduğu bildirilmiștir (Marco ve Vaughan 2005). Çalışmamızda her ne kadar TRSM takip süresi ile TRSM sonrası acil servis başvuru sayıları arasında pozitif bir korelasyon saptanmıș olsa da, bu ilişkinin zayıf olduğu görülmektedir. Toplum ruh sağlığı merkezi takibi sonrası acil başvurusu olan hasta miktarının ve acil başvuru sayısının anlamlı düzeyde düşmüş olması da dikkate alındığında, bu durumun küçük bir hasta grubunda TRSM takibi neticesi artmış tedavi katılımının yarattığı muhtemel endikasyon dışı acil servis müracaatlarından kaynaklı olabileceği düşünülmektedir. Ayrıca ilgili verilerin homojen dağılmamış olması da bu olasılığı güçlendirmektedir. Bununla birlikte TRSM takip süresi ile TRSM öncesi acil başvuru sayısı arasında, TRSM öncesi ve sonrası acil başvuruları arasında bir ilişkinin saptanmamış olması da bu nedenselliği desteklemektedir.

Hastane yatış oranlarına bakıldığında çalışmalar şizofrenide düşük tedavi katılımı ile birlikte yüksek hastane yatıs oranları bildirmektedir (Sun ve ark. 2007). Ayrıca yapılan çalışmalar tedavi maliyetleri açısından da yatırılarak tedavi giderlerinin oldukça önemli bir yük oluşturduğunu göstermektedir (de Macedo Rodrigues ve ark. 2016). Uzunlamasına çalışmalarda istemsiz yatışların tedavi sürecini ve hasta hekim ilişkini olumsuz etkilediği gösterilmiştir (Lay ve ark. 2018). Zorunlu psikiyatrik tedavileri azaltmaya yönelik müdahalelerin değerlendirildiği yakın tarihli bir meta analizde zorunlu tedavi kararlarının özellikle batılı ülkelerde artma eğiliminde olduğu, toplum odaklı uygulamaların zorunlu tedavi oranlarını azaltmadığı, geleceğe odaklı tedavi direktifi uygulamalarının ise bu noktada azaltıcı etkisi olduğu ifade edilmiștir (de Jong ve ark. 2016). Bu noktadan hareketle, dünyada psikiyatri pratiğinde, şizofreni hastalarının yönetiminde depo ilaç tedavileri gibi uygulamaların yanında yatış oranlarını azaltmaya yönelik psikoeğitim, kriz çözüm ekipleri ve toplum temelli ruh sağlığı uygulamaları gibi çeşitli programlar geliştirilmeye başlanmıştır (Lay ve ark. 2015; Lay ve ark. 2018). Çalışmamızın sonuçları da gerek toplam yatış sayıları gerekse istemsiz yatış sayıları açısından TRSM uygulamalarının olumlu katkısı olduğunu ve bu sayede yatırılarak tedavi tercihlerinin hastalar ve tedavinin gidişatı üzerinde yaratabileceği olumsuz etkilerin ortaya çıkmasını engelleyici rolü olduğunu destekler niteliktedir.

Bilindiği üzere TRSM uygulamaları tıbbi tedavilerin düzenlenmesi ve takibinin yanında hastaların yaşam kalitelerini ve işlevselliklerini artırmaya yönelik çeşitli müdahaleleri de kapsamaktadır. İşsizlik, yalnız yaşam gibi faktörler şizofrenide tedavi katılımını ve hastalık gidişini olumsuz etkileyen faktörler olarak bildirilmiştir (de Macedo Rodrigues ve ark. 2016; Lay ve ark. 2015). Hekim kararlılığının ve hakimiyetinin yetersizliği gibi faktörlerin de zorunlu tedavilerin öncülleri arasında olduğu bildirildiğinden, TRSM uygulamalarındaki hasta hekim ilișkilerinin kritik rolü hastaların zorunlu tedavi uygulamalarına maruz kalmamaları açısından önem arz etmektedir (de Jong ve ark. 2017). Ayrica metabolik hastalıklar başta olmak üzere çeşitli genel sağlık sorunlarının şizofreni hastalarında sık olduğu ve genel sağlık sorunlarının takibi açısından da toplum temelli ruh sağlığ merkezlerinin önemli rol oynadığ $\breve{1}$ bildirilmiştir (Putz ve ark. 2015).

Çalışmada bir diğer bulgu ise madde kullanımı öyküsünün ve vesayet kararının TRSM takibinde olmayan şizofreni hastalarında daha yüksek oranda olduğudur. Şizofrenide madde kullanımının kötü gidişat, tedavi katılımında düşüklük ve yüksek yatıs oranları ile ilişkili olduğu bilinmektedir (de Macedo Rodrigues ve ark. 2016; Shim ve ark. 2017). Madde kullanımına yönelik mücadelede de TRSM uygulamalarına benzer şekilde toplum temelli ruh sağlığ hizmetlerinin önemi her geçen gün artmaktadır (Annamalai ve ark. 2018; Shim ve ark. 2017). Her ne kadar çalışmamızda madde kullanımı öyküsü TRSM takibinde olmayan hastalarda daha yüksek oranda bulunmuşsa da, bu durumun madde kullanımı ve tedaviye katılım arasındaki negatif yönlü ilișkiden mi kaynaklandığı, yoksa TRSM takibine alınan hasta profilinin belirlenmesinde yapılmış olası bir yanlılıktan mı kaynaklandığı çalışmanın verileri ışığında netleştirilememiştir. Vesayet kararının da aynı şekilde TRSM takibinde olmayan hastalarda daha çok alınmış olması da, bu hasta grubunun daha kötü gidiş göstermesinden mi kaynaklandığı, yoksa vesayet kararı sonrası hastaların TRSM takibine alınma gerekliliğinde azalmayla mı ilişkili olduğu cevaplanabilmiş değildir.

Çalışmanın kısıtlılıklarına bakıldığında, geriye dönük tarama desenli bir çalışma olması, örneklem sayısının azlığı, verilerin sadece kayıtlar üzerinden toplanmış olması, kısıtlı bir zaman diliminde yapılmış müracaatların değerlendirilmesi olarak sıralanabilir. Veri yetersizliği yada dışlama kriterleri nedeni ile çalışmaya dahil 
edilmeyen hasta verileri bulguların yanlılığ karıştırıcı bir faktör olarak karşımıza çıkmaktadır. Çalışmanın tasarımına bağlı olarak hastalık şiddeti ile ilişkili ölçeklerin çalışmaya dahil edilememiş olması da bir diğer kısıtlılıktır. Ayrıca çalışmanın geriye dönük kesitsel tasarımı sebebiyle bulguların değerlendirilmesinde ters nedensellik faktörü de dışlanamamaktadır. $\mathrm{Bu}$ nedenle TRSM takibi sonrası gözlenen klinik iyileşme bulgularının direk TRSM etkisiyle mi olduğu, yoksa klinik iyilik halinin görece yüksek olduğu hastaların mı TRSM tarafindan takip edildiği çalışmamızın bulguları dahilin de netleştirilememektedir. Ayrıca TRSM uygulamalarının niteliği hususunda da herhangi bir değerlendirme yapılmamıştır. Diğer birçok alanda olduğu gibi psikiyatrik hasta grubunda da acil servise müracaatların sadece acil nedenlerle değil rutin poliklinik işlemlerini de gerçekleştirebilmek maksadıyla olabildiğini, bu bağlamda TRSM takibinde olan hastaların acil servisleri daha az kullanmış olma ihtimalini dikkate almak gereklidir. Bununla beraber çalışmaya özellikle en az bir kez yatırılarak tedavi görmüş olan şizofreni hastalarının alınmış olmasındaki amaç, TRSM takibine alınan hastaların büyük çoğunluğunun ileri derecede akıl hastalığı olduğu düşünüldüğünde daha homojen bir örneklem grubu oluşturulabilmektir.

\section{Sonuç ve Öneriler}

Sonuç olarak çalışma, TRSM uygulamalarının şizofreni hastalarında gerek yatış sayıları, gerek acil başvuruları gibi değişkenler ele alındığında faydalı uygulamalar olduğunu destekler niteliktedir. Ülkemizde giderek artan sayıda TRSM hizmetlerinin şizofreni hastalarına ulaşımının, teorik olarak toplum temelli ruh sağlığı eylem planının öngördüğü şekilde eder etkinlik, tedavi katılımında artış ve daha az alevlenmelerle ilişkili olacağı değerlendirilse de çalışmamız bu faktörlerin veriler üzerinden tanımlanarak somut şekilde ortaya koyması açısından önemlidir. $\mathrm{Bu}$ çalışmanın sunduğu veriler ışı ̆̆ında, ruh sağlığı çalışanlarına, özellikle kronik nitelik kazanmış, sık müracaatları ve yatış kararları olan, tedavi katılımı yetersiz şizofreni hastalarında TRSM uygulamalarına daha öncelikli ve sı şekilde yer vermelerini önermekteyiz. Bu nedenle, toplum ruh sağlı̆̆ merkezlerinin ruh sağlığı uygulamalarındaki etkilerini ve katkılarını ortaya koyabilmek ve bu alanda farkındalığı artırabilmek için daha geniş örneklemlerin olduğu ve daha iyi tasarlanmış kapsamlı çalı̧̧malara ihtiyaç olduğunu değerlendirmekteyiz.

\section{Kaynaklar}

Alatas, G., Karaoğlan, A., Arslan, M. ve Yanık, M. (2009). Toplum Temelli Ruh Sağlığı Modeli ve Türkiye'de Toplum Ruh Sağlığı Merkezleri Projesi, Archives of Neuropsychiatry/Noropsikiatri Arsivi, Suppl. 4625-29.

Annamalai, A., Staeheli, M., Cole, R.A. ve Steiner, J.L. (2018). Establishing an Integrated Health Care Clinic in a Community Mental Health Center: Lessons Learned, Psychiatr Q, 89(1), 169-181.

Asher, L., Hanlon, C., Birhane, R., Habtamu, A., Eaton, J., Weiss, H.A., Patel, V., Fekadu, A. ve De Silva, M. (2018). Community-based rehabilitation intervention for people with schizophrenia in Ethiopia (RISE): a 12 month mixed methods pilot study, BMC Psychiatry, 18(1), 250.

de Jong, M.H., Kamperman, A.M., Oorschot, M., Priebe, S., Bramer, W., van de Sande, R., Van Gool, A.R. ve Mulder, C.L. (2016). Interventions to Reduce Compulsory Psychiatric Admissions: A Systematic Review and Meta-analysis, JAMA Psychiatry, 73(7), 657-664.

de Jong, M.H., Oorschot, M., Kamperman, A.M., Brussaard, P.E., Knijff, E.M., van de Sande, R., Van Gool, A.R. ve Mulder, C.L. (2017). Crucial factors preceding compulsory psychiatric admission: a qualitative patient-record study, BMC Psychiatry, 17(1), 350

de Macedo Rodrigues, L.S., Soares Santos, A., Guerra Júnior, A.A., Mascarenhas Alemão, M., de Oliveira, H.N., Afonso Reis, E., Leal Vidal, C.E. ve Ruas Brandão, C.M. (2016). Hospitalization of schizophrenic patients in the public health system of Minas Gerais, Brazil, JBES: Brazilian Journal of Health Economics/Jornal Brasileiro de Economia da Saúde, $8(3)$.

Ensari, H., Gültekin, B.K., Karaman, D., Koç, A. ve Beşkardeş, A.F. (2013). Bolu Toplum Ruh Sağlığı Merkezi hizmetlerinin şizofreni hastalarındaki yaşam kalitesi, yeti yitimi, genel ve sosyal işlevsellik üzerine etkisi: Bir yıllık izleme sonuçları, Anatolian Journal of Psychiatry/Anadolu Psikiyatri Dergisi, 14(2), 108-114.
Hughes, R., Hayward, M. ve Finlay, W. (2009). Patients' perceptions of the impact of involuntary inpatient care on self, relationships and recovery, Journal of Mental Health, 18(2), $152-160$.

Jaeger, S., Pfiffner, C., Weiser, P., Langle, G., Croissant, D., Schepp, W., Kilian, R., Becker, T., Eschweiler, G. ve Steinert, T. (2013). Long-term effects of involuntary hospitalization on medication adherence, treatment engagement and perception of coercion, Soc Psychiatry Psychiatr Epidemiol, 48(11), 17871796.

Law, M.R., Soumerai, S.B., Ross-Degnan, D. ve Adams, A.S. (2008). A longitudinal study of medication nonadherence and hospitalization risk in schizophrenia, J Clin Psychiatry, 69(1), 47-53.

Lay, B., Blank, C., Lengler, S., Drack, T., Bleiker, M. ve Rossler, W. (2015). Preventing compulsory admission to psychiatric inpatient care using psycho-education and monitoring: feasibility and outcomes after 12 months, Eur Arch Psychiatry Clin Neurosci, 265(3), 209-217.

Lay, B., Kawohl, W. ve Rossler, W. (2018). Outcomes of a psycho-education and monitoring programme to prevent compulsory admission to psychiatric inpatient care: a randomised controlled trial, Psychol Med, 48(5), 849-860.

Lee, S., Chiu, M.Y., Tsang, A., Chui, H. ve Kleinman, A. (2006). Stigmatizing experience and structural discrimination associated with the treatment of schizophrenia in Hong Kong, Soc Sci Med, 62(7), 1685-1696.

Marco, C.A. ve Vaughan, J. (2005). Emergency management of agitation in schizophrenia, Am J Emerg Med, 23(6), 767-776.

Putz, J.W., Sapir, H.E., Macy, J.T., Lieberman, T.E., Forster, S.E., Reece, M., Mathes, K.A., Sheese, M., Andry, J.M. ve Frasure, K.A. (2015). Integrated healthcare in a communitybased mental health center: A longitudinal study of metabolic risk reduction, Journal of Social Service Research, 41(5), 584593. 
Shim, R.S., Compton, M.T., Zhang, S., Roberts, K., Rust, G. ve Druss, B.G. (2017). Predictors of Mental Health Treatment Seeking and Engagement in a Community Mental Health Center, Community Ment Health J, 53(5), 510-514.

Sun, S.X., Liu, G.G., Christensen, D.B. ve Fu, A.Z. (2007). Review and analysis of hospitalization costs associated with antipsychotic nonadherence in the treatment of schizophrenia in the United States, Current medical research and opinion, 23(10), 2305-2312.

Thornicroft, G.T.M. (2003). What are the arguments for community-based mental health care? . Copenhagen, WHO Regional Office for Europe, Copenhagen, WHO Regional Office for Europe.
Tsigebrhan, R., Shibre, T., Medhin, G., Fekadu, A. ve Hanlon, C. (2014). Violence and violent victimization in people with severe mental illness in a rural low-income country setting: a comparative cross-sectional community study, Schizophr Res, 152(1), 275-282.

Yanık, M. (2007). Türkiye ruh sağlığı sistemi üzerine değerlendirme ve öneriler, ruh sağlığı eylem planı önerisi, Reviews, Cases And Hypotheses in Psychiatry Özel Saylsı, 1(3), 9-78. 